\title{
Cladomarine, a new anti-saprolegniasis compound isolated from the deep-sea fungus, Penicillium coralligerum YK-247
}

\author{
Konami Takahashi ${ }^{1,2,3}$, Kazunari Sakai ${ }^{3}$, Yuriko Nagano $^{2}$, Sakiko Orui Sakaguchi ${ }^{2}$, Andre O Lima ${ }^{4}$, \\ Vivian H Pellizari $^{5}$, Masato Iwatsuki ${ }^{3,6}$, Kiyotaka Takishita ${ }^{1,2}$, Kenichi Nonaka ${ }^{3,6}$, Katsunori Fujikura ${ }^{2}$ \\ and Satoshi Ōmura ${ }^{3}$
}

The Journal of Antibiotics (2017) 70, 911-914; doi:10.1038/ja.2017.58; published online 31 May 2017

The Saprolegniaceae belongs to the Oomycota; among a member of this family, Saprolegnia parasitica is a virulent pathogen of fishes and their ova, and causes enormous damage and losses in the freshwater aquaculture, ${ }^{1,2}$ such as a salmon hatchery. In fish farms, saprolegniasis has been controlled by malachite green, effectively preventing infection. However, malachite green has been banned in many countries because it was found to be mutagenic. Bronopol is sometimes used as an alternative anti-saprolegniasis agent, but is not as effective as malachite green and is toxic to zooplankton and phytoplankton. ${ }^{3,4}$ Therefore, new anti-saprolegniasis compounds are urgently needed.

Fungi are rich sources of useful chemical compounds and mycotoxins, and are often explored to discover new useful substances. The fungi inhabit various environments, from land to sea. Remarkably, diverse fungi are present in deep-sea environments, in spite of the fact that the conditions in deep-sea environments are characterized by high pressure, low temperature and oligotrophy. ${ }^{5,6}$ The extreme conditions may affect the production of primary and secondary metabolites in deep-sea fungi, and therefore, there is a high probability that they produce structurally and functionally unique metabolites. ${ }^{7}$ Indeed, novel bioactive secondary metabolites from deep-sea fungi are increasingly being reported. ${ }^{8-10}$

On screening 546 cultured broths of 91 deep-sea fungal strains, we discovered that Penicillium coralligerum YK-247 could produce compounds with notable anti-Saprolegnia parasitica activity. Chromatographic fractionation of the cultured broth led to the isolation of a new compound, named cladomarine (1), together with two known compounds, cladosporin $(2)^{11}$ and $5^{\prime}$-hydroxyasperentin $(3)^{12}$ (Figure 1a). This study describes the taxonomy of the producing fungal strain, together with the fermentation, isolation, structure elucidation and anti-Saprolegnia parasitica activity of 1, 2 and 3.
Strain YK-247 was isolated from a sea cucumber collected at São Paulo Plateau, off Brazil (water depth: $3064 \mathrm{~m}$, sampling site: $28^{\circ} 29.9^{\prime} \mathrm{S}$ and $41^{\circ} 39.3^{\prime} \mathrm{W}$ ), using the human-occupied vehicle Shinkai 6500 of JAMSTEC under Japan-Brazil cooperative deep-sea investigation named Iatá-Piúna cruise. For determination of the morphological characteristics of the strain YK-247, slides were prepared from colonies grown on malt extract agar (MEA). Conidiophores were borne on a basal felt or directly from the agar, simple, smooth, 40-110 $\mu \mathrm{m}$ long, with a thick wall. Penicilli were typically biverticillate, sometimes monoverticillate or terverticillate. Metulae in whorls of 2-4, which were usually relatively appressed, sometimes slightly divergent when forced apart by larger whorls, $\sim 10.5-15.5 \times 3.0-4.8 \mu \mathrm{m}$ near the top, individually more or less cylindrical. Phialides were acerose, $8.0-12.5 \times 2.2-3.7 \mu \mathrm{m}$. Conidia borne in chains were globose, subglobose to ellipsoidal, slightly roughened, $3.0-4.0 \times 2.3-3.7 \mu \mathrm{m}$. The internal transcribed spacer (ITS) of ribosomal RNA gene of strain YK-247 was sequenced and its sequence was deposited at the DNA Data Bank of Japan (DDBJ) with the accession number LC214562. The ITS sequence of YK-247 was compared to sequences in the GenBank database by BLASTN 2.5.1 analysis. $^{13}$ The ITS sequence of YK-247 was $99.8 \%$ similar to that of CBS 123.65 (ex-type of Penicillium coralligerum; GenBank accession number NR_111666). Based on the results of morphological characteristics and ITS sequence, the strain YK-247 was identified as a strain of Penicillium coralligerum.

A loop of spores from a colony growing on a Miura's medium (LcA) slant was inoculated into $10 \mathrm{ml}$ of GP seed medium $\left(2.0 \%\right.$ glucose, $0.2 \%$ yeast extract, $0.5 \% \quad \mathrm{MgSO}_{4} \cdot 7 \mathrm{H}_{2} \mathrm{O}, \quad 0.5 \%$ Polypeptone, $0.1 \% \mathrm{KH}_{2} \mathrm{PO}_{4}$ and $0.1 \%$ agar, $\mathrm{pH}$ 6.0) in a test tube and incubated at $27^{\circ} \mathrm{C}$ for 3 days on a shaker at 300 r.p.m. The seed-culture $(10 \mathrm{ml})$ was inoculated into $500 \mathrm{ml}$-Erlenmeyer

${ }^{1}$ Graduate School of Marine Science and Technology, Tokyo University of Marine Science and Technology, Tokyo, Japan; ${ }^{2}$ Department of Marine Biodiversity Research, Japan Agency for Marine-Earth Science and Technology (JAMSTEC), Kanagawa, Japan; ${ }^{3}$ Kitasato Institute for Life Sciences, Kitasato University, Tokyo, Japan; ${ }^{4}$ Department of Biological Sciences, University of Vale do Itajaí, CTTMar, R Uruguai, Santa Catarina, Brazil; ${ }^{5}$ Institute of Oceanography, University of São Paulo, Sao Paulo, Brazil and ${ }^{6}$ Graduate School of Infection Control Sciences, Kitasato University, Tokyo, Japan

Correspondence: Dr K Nonaka or Professor S Ōmura, Kitasato Institute for Life Sciences, Kitasato University, 5-9-1 Shirokane, Minato-ku, Tokyo 108-8641, Japan.

E-mail: ken@lisci.kitasato-u.ac.jp or omuras@insti.kitasato-u.ac.jp

Received 23 January 2017; revised 6 April 2017; accepted 20 April 2017; published online 31 May 2017 
<smiles>[R7]c1c(O)cc(O)c2c1C[C@H](C[C@H]1CC[C@@H]([R6])[C@@H](C)O1)OC2=O</smiles><smiles>[R][R]([H])=[R][R](=[R])[H]</smiles>

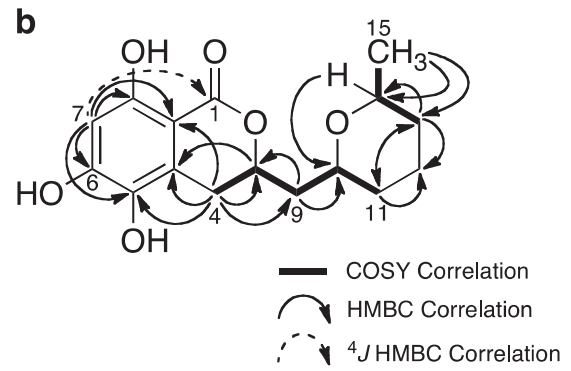

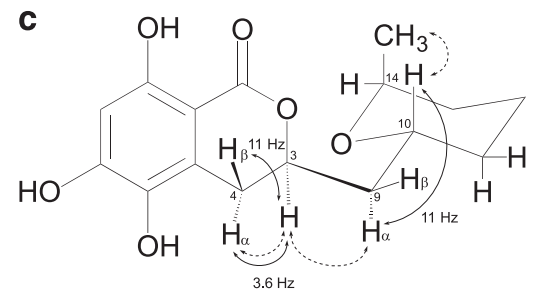

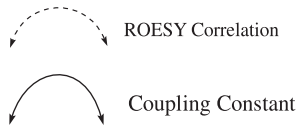

Figure 1 (a) Structure of (1) cladomarine, (2) cladosporin and (3) 5'-hydroxyasperentin. (b) COSY and HMBC correlation of (1) cladomarine. Bold lines show ${ }^{1} \mathrm{H}-{ }^{1} \mathrm{H}$ correlation, arrows show ${ }^{1} \mathrm{H}-{ }^{13} \mathrm{C}$ correlation and dotted arrows show ${ }^{4} \mathrm{~J} \mathrm{HMBC}$. (c) ROESY correlation and coupling constant of (1) cladomarine. Arrows show ${ }^{1} \mathrm{H}$ coupling constant and dotted arrows show ROESY correlation.

flasks, each containing $50 \mathrm{~g}$ of rice medium was immersed in seawater for $2 \mathrm{~h}$ and sterilized (three flasks, total $150 \mathrm{~g}$ ) and static fermentation occurred for 13 days. The cultured rice medium $(150 \mathrm{~g})$ was subsequently added to $300 \mathrm{ml}$ of ethanol and then filtered. The filtrate was concentrated under reduced pressure to remove ethanol and extracted with EtOAc $(300 \mathrm{ml})$ three times. The EtOAc extract $(365.3 \mathrm{mg})$ was applied to an octadecylsilane (ODS) gel column $(20 \varphi \times 100 \mathrm{~mm}$, YMC Co. Ltd., Kyoto, Japan). The column was eluted stepwise with $\mathrm{CH}_{3} \mathrm{OH}-\mathrm{H}_{2} \mathrm{O}(0,30,50,60,70,80$ and 100\%) and fractionated. The $60 \% \mathrm{CH}_{3} \mathrm{OH}$ aq. fraction $(39.7 \mathrm{mg}$ ) was purified by HPLC (Pegasil ODS SP100 $(20 \varphi \times 250 \mathrm{~mm})$ Senshu Scientific Co. Ltd., Tokyo, Japan) with $40 \% \mathrm{CH}_{3} \mathrm{OH}$ aq. at a flow rate of $7 \mathrm{ml} \mathrm{min}-1$, using detection by UV $210 \mathrm{~nm}$ to obtain 1 (4.8 $\mathrm{mg}$, $\left.R_{\mathrm{t}}=29 \mathrm{~min}\right)$ and $2\left(12.1 \mathrm{mg}, R_{\mathrm{t}}=48 \mathrm{~min}\right)$. The $50 \% \mathrm{CH}_{3} \mathrm{OH}$ aq. fraction $(18.0 \mathrm{mg})$ was separated by silica gel column $(1.8 \varphi \times 25 \mathrm{~mm}$, Merck KGaA, Darmstadt, Germany) with $\mathrm{CHCl}_{3}-\mathrm{CH}_{3} \mathrm{OH}(100 / 0$, $100 / 1,100 / 3,100 / 5,9 / 1,1 / 1$ and $0 / 100$ ). The 100/5 fraction was evaporated under reduced pressure to yield $3(3.3 \mathrm{mg})$.

The molecular formulae of $\mathbf{2}$ and $\mathbf{3}$ were elucidated by ESI-MS to be $\mathrm{C}_{16} \mathrm{H}_{20} \mathrm{O}_{5}$ and $\mathrm{C}_{16} \mathrm{H}_{20} \mathrm{O}_{6}$, respectively. The analyses of ${ }^{1} \mathrm{H},{ }^{13} \mathrm{C}$ and $2 \mathrm{D}$ NMR spectra data led to the identification of 2 and 3 as cladosporin ${ }^{11}$ and $5^{\prime}$-hydroxyasperentin, ${ }^{12}$ respectively.

Physico-chemical properties of $\mathbf{1}$ are shown in Supplementary Table S2. Compound 1 was obtained as dark yellow oil (UV $\left(\mathrm{CH}_{3} \mathrm{OH}\right)$ $\lambda \max \mathrm{nm}(\varepsilon)$ : 207 (12104), 232 (7515), 272 (5513) and 328 (3819)). The molecular formula of 1 was elucidated as $\mathrm{C}_{16} \mathrm{H}_{20} \mathrm{O}_{6}$ with seven degrees of unsaturation by a high-resolution electron spray ionization mass spectrometer $\left(\mathrm{m} / \mathrm{z} 307.1185[\mathrm{M}-\mathrm{H}]^{-}\right.$(calcd. for $\mathrm{C}_{16} \mathrm{H}_{19} \mathrm{O}_{6}$, 307.1182)). The IR characteristic absorptions of 1 at 3276, 2923, 2852, 1637, 1199, 1089 and $1016 \mathrm{~cm}^{-1}$ suggested the presence of hydroxyl and carbonyl groups. The ${ }^{1} \mathrm{H}$ and ${ }^{13} \mathrm{C}$ NMR spectra of 1 in $\mathrm{CD}_{3} \mathrm{OD}$ are summarized in Table 1 . Analyses of ${ }^{1} \mathrm{H},{ }^{13} \mathrm{C}$ NMR and HMQC spectra indicated the presence of one $s p^{3}$ methyl group, three $s p^{3}$ oxymethine groups, five $s p^{3}$ methylene groups and seven $s p^{2}$ carbons (including one carbonyl and six aromatic carbons, which suggested the presence of a benzene ring). The ${ }^{1} \mathrm{H}-{ }^{1} \mathrm{H}$ COSY analysis revealed two partial structures, from $\mathrm{H}_{2}-4$ to $\mathrm{H}_{2}-11$ and from $\mathrm{H}_{2}-13$ to $\mathrm{H}_{3}-15$. The $\mathrm{HMBC}$ correlations from $\mathrm{H}_{3}-15$ to $\mathrm{C}-14$ and $\mathrm{C}-13$, from
$\mathrm{H}_{2}-14$ to $\mathrm{C}-10$ and from $\mathrm{H}_{2}-11$ to $\mathrm{C}-13$ and $\mathrm{C}-12$ suggested the presence of 2-methyltetrahydro- $2 \mathrm{H}$-pyran ring including two partial structures. Moreover, the $\mathrm{HMBC}$ correlations from $\mathrm{H}_{2}-4$ to C-3, C-4a, C-5, C-8a and C-9 and from H-7 to C-1, C-8a, C-8, C-6 and C-5 revealed that 1 has a 6, 7, 9-trihydroxy-3, 4-dihydroisocoumarin skeleton and should be a new analog of 2 (Figure $1 \mathrm{~b}$ ). The comparison of the ${ }^{13} \mathrm{C}$ chemical shifts at C-6 $\left(\delta_{\mathrm{C}} 155.6\right)$ and C-8 $\left(\delta_{\mathrm{C}} 159.0\right)$ with those reported in literature, ${ }^{14,15}$ confirmed the presence of this skeleton.

The relative configuration of $\mathbf{1}$ was established by ROESY correlations and coupling constants (Figure 1c). ROESY correlations of $\mathrm{H}-10 /$ $\mathrm{H}_{3}-15, \mathrm{H}-3 / \mathrm{H}-4 \alpha$ and $\mathrm{H}-3 / \mathrm{H}-9 \alpha$ and ${ }^{1} \mathrm{H}-{ }^{1} \mathrm{H}$ coupling constant of $\mathrm{H}-4 \beta / \mathrm{H}-3(10.9 \mathrm{~Hz}), \mathrm{H}-4 \alpha / \mathrm{H}-3(3.6 \mathrm{~Hz})$ and $\mathrm{H}-9 \alpha / \mathrm{H}-10(11 \mathrm{~Hz})$ the relative configuration of 1 should be $3 R^{\star}, 10 R^{\star}, 14 S^{\star}$, as shown in Figure 1c. Finally, the absolute configuration of 1 was determined to be the same $3 R, 10 R, 14 S$ by comparison of the optical rotation of 1 $(-12.9)$ with that of $2(-18.1)$, as reported in the literature. ${ }^{16}$ The CD spectra of 1 and 2 , with positive Cotton effect $(270 \mathrm{~nm})$, also supported this absolute configuration ${ }^{17}$ (Supplementary Figures S2-1, S2-2). The results described above confirmed that $\mathbf{1}$ is a new analog of cladosporin, which was named cladomarine.

Anti-oomycetes assays were carried out by a modification of previously reported methods. ${ }^{2,3}$ Anti-oomycetes activity against Saprolegnia parasitica kassil and another oomycete, Pythium sp. sakaril, was evaluated using the paper disc method ( $8 \mathrm{~mm}$, ADVANTEC, Tokyo, Japan). The two oomycete strains were isolated from Chum salmon hatcheries in Iwate Prefecture, Japan. Saprolegnia parasitica was cultured on glucose yeast extract (GY) seed medium $(0.25 \%$ yeast extract, $0.25 \%$ glucose and $0.2 \%$ agar) and cultured at $27^{\circ} \mathrm{C}$ for 2 days on a shaker at 300 r.p.m. The seed-culture (10\%) and GY agar $\left((0.25 \%\right.$ yeast extract, $0.25 \%$ glucose and $1.0 \%$ agar $\left.), 40{ }^{\circ} \mathrm{C}\right)$ were poured into plates and paper disks with samples for testing were placed to each plate. All samples were evaluated at three doses $(100,30$ and $10 \mu \mathrm{g})$. Plates were incubated at $27^{\circ} \mathrm{C}$ for $24 \mathrm{~h}$. The Pythium sp. assay was conducted identically. Cultural conditions were as follows; (vegetable juce medium (12\% vegetable juce (Kagome, Aichi, Japan) supernatant, $1.0 \%$ glucose and 1.0\% agar), $3.0 \%$ inoculation, $27^{\circ} \mathrm{C}, 24 \mathrm{~h}$ ). 
Table $1{ }^{1} \mathrm{H}$ and ${ }^{13} \mathrm{C}$ NMR data for cladomarine (1) (recorded at $400 \mathrm{MHz}{ }^{1} \mathrm{H}$ NMR and $100 \mathrm{MHz}{ }^{13} \mathrm{C}$ NMR in $\mathrm{CD}_{3} \mathrm{OD} ; \delta$ in p.p.m.)

\begin{tabular}{|c|c|c|}
\hline \multirow[b]{2}{*}{ Position } & \multirow[b]{2}{*}{${ }^{13} \mathrm{C}$} & 1 \\
\hline & & ${ }^{1} H(J$ in $H z)$ \\
\hline 1 & 171.8 & - \\
\hline 2 & - & - \\
\hline 3 & 77.7 & 4.61 (dddd, 3.6, 3.8, 9.1, 10.9) \\
\hline $4 \alpha$ & 28.5 & $3.17(\mathrm{dd}, 3.6,16.9)$ \\
\hline $4 \beta$ & & $2.66(\mathrm{dd}, 10.9,16.9)$ \\
\hline $4 a$ & 126.1 & - \\
\hline 5 & 135.7 & - \\
\hline 6 & 155.6 & - \\
\hline 7 & 101.8 & $6.27(\mathrm{~s})$ \\
\hline 8 & 159.0 & - \\
\hline $8 a$ & 100.2 & - \\
\hline $9 \alpha$ & 39.3 & $2.15(\mathrm{ddd}, 3.8,11.0,14.9)$ \\
\hline $9 \beta$ & & $1.8(\mathrm{ddd}, 3.0,9.1,14.9)$ \\
\hline 10 & 68.3 & $4.14(\mathrm{~m})$ \\
\hline \multirow[t]{2}{*}{11} & 31.4 & $1.35(\mathrm{~m})$ \\
\hline & & $1.73(\mathrm{~m})$ \\
\hline \multirow[t]{2}{*}{12} & 19.3 & $1.70(\mathrm{~m})$ \\
\hline & & $1.70(\mathrm{~m})$ \\
\hline \multirow[t]{2}{*}{13} & 32.7 & $1.32(\mathrm{~m})$ \\
\hline & & $1.70(\mathrm{~m})$ \\
\hline 14 & 68.3 & $3.92(\mathrm{~m})$ \\
\hline 15 & 20.0 & $1.18(\mathrm{~d}, 6.0)$ \\
\hline
\end{tabular}

Measured in $\mathrm{CD}_{3} \mathrm{OD}$.

Antimicrobial activities against two bacteria, a filamentous fungus and a yeast were also measured to reveal any selectivity differences between anti-S. parasitica activity and antimicrobial activity. All assays were carried out using the paper disc method described previously. ${ }^{18}$ Test organisms (two bacteria and two fungi) used were as follows, Bacillus subtilis ATCC 6633, Pseudomonas aeruginosa NBRC 12582, Aspergillus niger ATCC 6275 and Candida albicans ATCC 64548.

We also determined the MIC of 1, 2 and 3 against $S$. parasitica. MIC assay was carried out with a modification of previously reported methods. ${ }^{2,3}$ Saprolegnia parasitica was cultured on corn meal agar $\left(0.2 \%\right.$ corn meal and $1.5 \%$ agar) at $15^{\circ} \mathrm{C}$ for 5 days. $9 \mathrm{ml}$ of GY agar $(0.25 \%$ yeast extract, $0.25 \%$ glucose and $1.0 \%$ agar) and $1 \mathrm{ml}$ of sample solution in $50 \% \mathrm{CH}_{3} \mathrm{OH}$ aq. was poured into a plate, with the final concentrations of samples being $\left(64,32\right.$ and $\left.16 \mu \mathrm{g} \mathrm{ml}^{-1}\right)$. Subsequently, a corn meal agar seed cultured block of $S$. parasitica was put on each plate; the plates were incubated at $27^{\circ} \mathrm{C}$ for $24 \mathrm{~h}$. A solution of malachite green (fin. $25 \mu \mathrm{g} \mathrm{ml}^{-1}$ ) was used as a positive control. The growth of $S$. parasitica was checked by observation to determine the MIC values.

Antimicrobial activities of $\mathbf{1}, \mathbf{2}$ and $\mathbf{3}$ are summarized in Table 2. Among them, 2 was the most potent against S. parasitica (an MIC value of $2 \mu \mathrm{g} \mathrm{m}^{-1}$ ) along with Pythium sp. but was not active against the other organisms tested. Compound $\mathbf{1}$ was slightly active against the two oomycetes, while $\mathbf{3}$ did not show any activity. Structurally, because of the lack of a hydroxyl group, $\mathbf{2}$ is more hydrophobic than $\mathbf{1}$ and $\mathbf{3}$. The difference between $\mathbf{1}$ and $\mathbf{3}$ is the position of a hydroxyl group, at C-5 and C-13, respectively. The high hydrophobicity of 2 may be important in affecting anti-oomycete activity. In addition, these compounds are more selective against the two oomycetes tested than malachite green, exhibiting a narrower antimicrobial activity. The results suggest that the cladosporin analog could be a promising
Table 2 Antimicrobial activity of cladomarine (1), cladosporin (2) and 5 '-hydroxyasperentin (3)

\begin{tabular}{lcccc}
\hline & \multicolumn{5}{c}{$10 \mu \mathrm{g}$ per disc $\left(\mathrm{MIC}: \mu \mathrm{g} \mathrm{ml^{-1 } )}\right.$} \\
\cline { 2 - 5 } Organism & $\mathbf{1}$ & $\mathbf{2}$ & $\mathbf{3}$ & Malachite green \\
\hline Saprolegnia parasitica & $13(>64)$ & $23(2)$ & $-(>64)$ & 36 \\
Pythium sp. & 12 & 26 & - & 38 \\
Bacillus subtilis & - & - & - & 27 \\
Pseudomonas aeruginosa & - & - & - & 10 \\
Aspergillus niger & - & - & - & 32 \\
Candida albicans & - & - & - & 24 \\
\hline
\end{tabular}

Inhibition zone (mm): no inhibition.

lead candidate for the development of a new, less toxic compound to control saprolegniasis.

The mode of action on the anti-malarial activity of $\mathbf{2}$ was proposed to be inhibition of the Plasmodium falciparum lysyl-tRNA synthetase. ${ }^{19}$ However, Saccharomyces cerevisiae lysyl-tRNA synthetase is not inhibited by $2{ }^{19}$ This selectivity of 2 against lysyl-tRNA synthetase might be associated with that against oomycetes. Very recently, the biosynthesis of $\mathbf{2}$ was identified by genome sequencing of Cladosporium cladosporioides UAMH 5063, which also produces $2 .^{20}$ However, a gene encording an oxidase such as cytochrome P450 enzyme, which potentially oxidizes 2 at the C-5 position, were not found in the gene cluster of 2 . It seems likely that $P$. coralligerum YK-247, the producer of $\mathbf{1}$, has an additional oxidase gene, as well as a similar gene cluster.

In conclusion, we isolated three compounds, 1, 2 and 3, from a cultured broth of the deep-sea fungus $P$. coralligerum YK-247. Compounds 1 and 2 showed selective inhibition of the growth of S. parasitica, together with a second oomycete, Pythium sp. The results demonstrate that cladomarine and cladosporin analogs could be good lead candidates in the development of much-needed novel agents to control saprolegniasis, while also confirming that the deep-sea fungi are indeed promising sources for new drug discovery.

\section{CONFLICT OF INTEREST}

The authors declare no conflict of interest.

\section{ACKNOWLEDGEMENTS}

We are grateful to Dr Kenichiro Nagai (School of Pharmacy, Kitasato University) for measurement of MS, to Mr Hiromu Iwasaki (School of Science, Kitasato University) for assistance with fungal cultivation and observation, and to Dr Yukihiro Asami (Kitasato Institute for Life Sciences, Kitasato University) for support concerning this study, and to Dr Hiroshi Kitazato (JAMSTEC) for arranging research cruise of the Iatá-Piúna cruise. This work was supported by the research project Tohoku Ecosystem-Associated Marine Sciences from the Ministry of Education, Culture, Sports, Science and Technology.

1 West, P. V. Saprolegnia parasitica, an oomycete pathogen with a fishy appetite: new challenges for an old problem. Mycologist 20, 99-104 (2006).

2 Takada, K., Kajiwara, H. \& Imamura, N. Oridamycins A and B, anti-Saprolegnia parasitica indolosequiterpenes isolated from Streptomyces sp. KS84. J. Nat. Prod. 73, 698-701 (2010).

3 Nakagawa, K., Hara, C., Tokuyama, S., Takada, K. \& Imamura, N. Sapromycins A-E, new angucycline antibiotics active against Saprolegnia parasitica. J. Antibiot. 65, 559-607 (2012).

4 Ali, S. E., Thoen, E., Evensen, Q. \& Skaar, I. Boric acid inhibits germination and colonization of Saprolegnia spores in vitro and in vivo. PLOS ONE 9, e91878 (2014).

5 Zhang, X. Y., Zhang, Y., Xu, X. Y. \& Qi, S. H. Diverse deep-sea fungi from the South China Sea and their antimicrobial activity. Curr. Microbiol. 67, 525-530 (2013). 
6 Wang, Y. T., Xue, Y. R. \& Liu, C. H. A brief review of bioactive metabolites derived from deep-sea fungi. Mar. Drugs 13, 4594-4616 (2015).

7 Skropeta, D. Deep-sea natural products. Nat. Prod. Rep. 25, 1131-1166 (2013).

8 Niu, S., Liu, D., Proksch, P., Shao, Z. \& Lin, W. New polyphenols from a deep-sea Spiromastix sp. fungus, and their antibacterial activities. Mar. Drugs 13, 2526-2540 (2015).

9 Fredimoses, M. et al. New Prenylxanthones from the deep-sea derived fungus Emericella sp. SCSIO 05240. Mar. Drugs 12, 3190-3202 (2014).

10 Chen, X. W. et al. Nine new and five known polyketides derived from a deep sea-sourced Aspergillus sp. 16-02-1. Mar. Drugs 12, 3116-3137 (2014).

11 Jacyno, J. M., Harwood, J. S., Cutler, H. G. \& Lee, M. K. Isocladosporin, a biologically active isomer of cladosporin from Cladosporium cladosporioides. J. Nat. Prod. 56, 1397-1401 (1993).

12 Wang, X. et al. Antifungal activity against plant pathogens of metabolites from the endophytic fungus Cladosporium cladosporioides. J. Agric. Food Chem. 61, 4551-4555 (2013)

13 Altschul, S. F. et al. Gapped BLAST and PSI-BLAST: a new generation of protein database search programs. Nucleic. Acids. Res. 25, 3389-3402 (1997).
14 Takenaka, Y., Hamada, N. \& Tanahashi, T. Aromatic compounds from cultured lichen mycobionts of three Graphis species. Heterocycles 83, 2157-2164 (2011).

15 Tang, Q. et al. Three new asperentin derivatives from the algicolous fungus Aspergillus sp. F00785. Mar. Drugs 12, 5993-6002 (2014).

16 Rawlings, B. J., Reese, P. B., Ramer, S. E. \& Vederas, J. C. Comparison of fatty acid and polyketide biosynthesis: stereochemistry of cladosporin and oleic acid formation in Cladosporium cladosporioides. J. Am. Chem. Soc. 111, 3382-3390 (1989).

$17 \mathrm{Krohn}, \mathrm{K}$. et al. Dihydroisocoumarins from fungi: isolation, sturucture elucidation, circular dichroisum and biological activity. Phytochemistry 45, 313-320 (1997).

18 Iwatsuki, M. et al. Guadinomines, Type III secretion system inhibitors, produced by Streptomyces sp. K01-0509. II. Physico-chemical properties and structure elucidation. J. Antibiot. 61, 230-236 (2008).

19 Hoepfner, D. et al. Selective and specific inhibition of Plasmodium falciparum Lysyl-tRNA synthetase by the fungal secondary metabolite cladosporin. Cell Host Microbe 11, 654-663 (2012).

20 Cochrane, R. V. K. et al. Production of new cladosporin analogues by reconstitution of the polyketide synthases responsible for the biosynthesis of this antimalarial agent. Angew. Chem. Int. Ed. 55, 664-668 (2016).

Supplementary Information accompanies the paper on The Journal of Antibiotics website (http://www.nature.com/ja) 